\title{
O UNIFORME DA ENFERMEIRA VISTO PELO PACIENTE, ENFERMEIRA E DOCENTE DE ENFERMAGEM
}

\author{
Maria Júlia Paes da Silva* \\ Maguida Costa Stefanelli** \\ Lina Monetta*** \\ Thelma Leite de Araujo ${ }^{\star \star * *}$
}

SILVA, M.J.P. da et al. O uniforme da enfermeira visto pelo paciente, enfermeira e docente de enfermagem. Rev.Esc.Enf.USP, v.29, n.1, p.72-82, abr.1995.

O presente trabalho teve por objetivo verificar a percepção de pacientes, enfermeiras e docentes de enfermagem, de diferentes instituições de saúde, sobre a imagem da enfermeira baseada em modelos de uniformes mais comumente usados na cidade de São Paulo. A população do estudo foi de 100 pacientes, 30 enfermeiros e 15 docentes de enfermagem, pertencentes a instituições públicas e privadas da cidade de São Paulo. Os dados foram coletados através de 9 fotografias de uma enfermeira com a mesma expressão facial, mas com diferentes uniformes. Percebeu-se que a foto de maior aceitação para prestar cuidados, referida pelas três categorias, foi a da enfermeira com calça comprida e blusa branca. O uniforme mais rejeitado foi a saia acima do joelho, blusa e blazer brancos.

UNITERMOS: Uniformes. Comunicação não verbal

\section{INTRODUÇÃO}

O estudo da comunicação não verbal ganhou novo impulso nas últimas décadas. Uma razão para o interesse por essa área está, provavelmente, na importância deste assunto para entendermos melhor o relacionamento interpessoal.

Um dos grandes pesquisadores deste tema, BIRDWHISTELL (1970), concluiu, após muito tempo de estudo sobre a comunicação nãø verbal, que

\footnotetext{
* Prof.Dr. do Departamento de Enfermagem Médico-Cirúrgica da Escola de Enfermagem da USP.

** Professor Titular da Escola de Enfermagem da USP.

*** Enfermeira do Hospital Alemão Oswaldo Cruz. Mestranda da Escola de Enfermagem da USP.

**** Enfermeira. Mestre em Fundamentos de Enfermagem.
} 
esta se passa, em grande parte, abaixo da consciência, num nível em que a relevância das palavras é apenas indireta.

Segundo esse o mesmo autor, somente cerca de $35 \%$ do significado social de qualquer interação interpessoal corresponde as palavras pronunciadas; os outros $65 \%$ do conteúdo não são comunicados oralmente, e sim por meio de gestos, postura corporal, expressões faciais, distância interpessoal, entre outros (BIRDWHISTELL, 1970).

KNAPP (1980) e EYSENCK; EYSENCK (1981) apresentam uma revisão dos estudos científicos a respeito da influência da atração física nas relações interpessoais. Tais autores verificaram que há grande discrepância entre as declarações das pessoas, a respeito da importância que dão ao aspecto físico do outro, e seu comportamento em relação ao outro. Segundo tais declarações, obtidas através de entrevistas, questionários, etc, a aparência física influenciaria pouco as atitudes e ações em relação ao outro; o importante seria o caráter, a personalidade, as idéias do outro. Porém, a evidência mostrou que, de fato, a aparência física tem mais influência do que os outros fatores mencionados, na determinação de ações concretas.

Qualquer de nós pode ter tido a experiência, em um restaurante, por exemplo, de perceber somente o uniforme de um garçon e, mais tarde, no momento de chamá-lo, não saber quem servia a mesa. É razoável a suposição de que, quase sempre, nossa percepção dos demais é influenciada, em parte, pela sua roupa e em parte por outros fatores.

O papel exato da aparência e da vestimenta no sistema total da comunicação não verbal ainda nos é desconhecido. No entanto, sabemos que a aparência e a vestimenta são parte dos estímulos não verbais totais que influem nas respostas interpessoais, e que em certas ocasiões, são os determinantes principais de tais respostas (KNAPP, 1980; WEIL; TOMPAKOV, 1986).

KNAPP (1980) afirma que, para compreender a relação entre vestimenta e comunicação, deveríamos familiarizarmo-nos com as diferentes funções que a vestimenta pode ter: de decoração, proteção (tanto física como psicológica), atração sexual, auto-afirmação, auto-negação, "ocultamento", identificação grupal e exibição de status.

Visto que existem algumas regras de ampla aceitação social sobre a comunicação de certas cores c modelos, a roupa também pode desempenhar a função de informar ao observador sobre o conhecimento do usuário acerca dessas regras.

Alguns dos atributos pessoais que a roupa pode comunicar são: a idade, o sexo, o status socio-econômico, a identificação com um grupo específico, o status profissional, o humor, a personalidade, os interesses e os valores (KNAPP, 1980).

A certeza de tais julgamentos varia consideravelmente, e os itens mais 
concretos, tais como idade, sexo, nacionalidade e status sócio-econômico têm mais alto indice de acerto que as qualidades mais abstratas, tais como valores, interesses e personalidade.

KALISCH; KALISCH (1985) consideram que, além do tipo de roupa estar associado à ocupações específicas, como o uniforme azul ao policial, a roupa branca ao médico, a roupa preta com colarinho branco ao padre e assim por diante, ela também serve para predizer comportamentos e influenciar auto-conceito. Os mesmos autores descrevem a evolução histórica dos diferentes uniformes da enfermeira que, ao longo de 112 anos, sofreram modificações impostas pela moda da época, isto é, sem fugir dos modelos considerados elegantes, o uniforme pretendeu sempre identificar o enfermeiro como um profissional.

SANDOVAL (1990) fez uma pesquisa com pacientes cirúrgicos do sexo masculino, com o objetivo principal de verificar quais os signos hospitalares percebidos pelos pacientes. Dentre os signos mais mencionados e que apareceram com maior freqüência, está a roupa utilizada pelo médico e pelas demais pessoas do centro cirúrgico, o que nos mostra, mais uma vez, a importância da vestimenta na relação terapêuta com o paciente.

A roupa determina nossas expectativas de conduta sobre o usuário, especialmente quando se trata de um uniforme, ou seja, a roupa pode estimular ou desestimular certos assuntos na conversação.

Um traje novo pode promover sentimentos de alegria e satisfação e 6 possível que o indivíduo se sinta menos eficaz quando está usando sapatos que apertam ou um traje "inadequado" para a ocasião.

Além da vestimenta, toda pessoa utiliza uma quantidade de objetos e cosméticos, tais como insígnias, pinturas, jóias, entre outros, que também são estímulos comunicativos em potencial.

IIOGA (1991) fez um levantamento, através de entrevistas e fotografias, de como foi o uniforme preconizado pela Escola de Enfermagem da USP, para suas alunas, durante o período de 1944 a 1990 . Verificou, entre outros aspectos, que até 1978 o uniforme era branco e azul, sendo que a cor azul teve tons diferentes e foi usada como cor do vestido, do agasalho, ou como detalhe em listras na blusa. Até aproximadamente 1955, o comprimento das saias era 30 centímetros do chão, independente da estatura da aluna, e só em 1974 foi permitido o uso de calça comprida (sempre na cor branca). Em 1973 o uso da touca nos cabelos foi abolido.

Consideramos que as mudanças ocorridas ao longo dos anos estão diretamente relacionadas às mudanças comportamentais e culturais do país, sendo hoje observado que, apesar do branco "ser livre", ou seja, não termos um modelo de uniforme, mas apenas o uso do vestuário da cor branca como sendo a obrigatoriedade na Escola de Enfermagem, ainda se espera que as alunas usem o "bom senso" na escolha da vestimenta: que não seja transparente, muito justa, a saia muito curta, entre outros. 
KALISCH; KALISCH (1982) analisaram 204 filmes, em língua inglesa, realizados no período de 1930 ao início da década de 80 , onde aparecem enfermeiras ou onde a enfermeira é o foco da história. Encontraram em 55,3\% dos filmes a enfermeira com características positivas, espírito altruístico e de uniforme, na maioria das vezes branco, sempre com saia ou vestido e com a touca branca. Sabemos que no Brasil ainda existem instituições que mantêm a touca branca como uniforme, mas não são a maioria. Na grande parte das instituições de saúde, o uso da calça comprida também está liberado.

MELO (1990) procurou fotos de enfermeiras veiculadas em revistas nacionais da editora Abril (SP) e editora BLOCH (RJ) nos anos de 1987 a 1988, nada encontrando. Ela estudou a imagem do enfermeiro nos anúncios de publicidade, e como esses anúncios interferem na formação ou reforço de esterétipos negativos do grupo profissional. Trabalhou junto a vestibulandos com 5 fotos encontradas em revistas, onde a enfermeira aparece com touca em 3 delas e de branco em 4 delas. Quatro das fotos não permitem identificar se as enfermeiras estão de saia, vestido ou calça. Os resultados indicam que, nesse grupo específico, havia pouco conhecimento do que é a profissão.

MEADE (1980) relata a experiência de trabalhar sem uniforme junto a pacientes psiquiátricos, considerando que, apesar da justificativa da não utilização do mesmo ser a diminuição do distanciamento entre o paciente e a enfermeira, as situações do dia-a-dia na enfermaria exigem que ele seja usado para evitar confusões, constrangimentos e para que os pacientes se sintam seguros. Um dos exemplos citados por ela é o pessoal de enfermagem estar sujeito a entrar em contato com todos os tipos de secreções dos pacientes.

MEYER (1992), em recente pesquisa com crianças de 3, 4 e 5 anos, com e sem experiência de hospitalização, verificou, em 5 fotografias de enfermeiras com uniformes diferentes, quais elas gostariam que cuidassem delas, e se existia alguma que lhes despertasse medo. Verificou que a maioria das 100 crianças (de ambos os grupos - com ou sem hospitalização anterior) preferiu ser cuidada por enfermeira de calça comprida branca com uma bata colorida. Com relação a pergunta, se alguma daquelas fotos lhes despertava medo, encontrou em $50 \%$ das crianças com experiência hospitalar anterior e em $32 \%$ das crianças sem hospitalização anterior, a resposta "assustadora" para o tradicional uniforme de vestido branco com touca. A fotografia com calça comprida branca, sem touca, lhes pareceu menos assustadora que a foto com vestido branco.

Foi feita uma pesquisa por MANGUM et al (1991) com o objetivo de determinar as diferenças na percepção de pacientes, enfermeiras e administradores hospitalares quanto a imagem das enfermeiras vestidas com diferentes modelos de uniforme. Foi perguntado para 100 pacientes, 30 enfermeiras e 15 administradores hospitalares, para os quais foram mostradas 9 
(nove) fotos de enfermeira com diferentes uniformes, qual delas despertava maior confiabilidade, competência, atenção, eficiência, empatia, profissionalismo. Verificou-se que a percepção das três categorias citadas era diferente, a saber: os pacientes preferiram o uniforme vestido branco e touca; as enfermeiras e os administradores, preferiram calça e jaleco branco e estetoscópio no pescoço (como mostrava uma das fotos).

Com base nessas pesquisas, nos propusemos a desenvolver o presente estudo, com o objetivo de determinar a percepção de pacientes, enfermeiras e docentes de enfermagem, de diferentes instituições de saúde, quanto à imagem da enfermeira baseada em modelos de uniformes mais comumente usados na cidade de São Paulo.

Os resultados encontrados foram comparáveis aos dados encontrados por MANGUM et al. (1991), nos E.U.A.

\section{MÉTODO}

\section{População}

A população deste estudo constou de 100 pacientes, 30 enfermeiros e 15 docentes de enfermagem, pertencentes a diferentes instituições públicas e privadas da cidade de São Paulo. Todos os participantes da população puderam decidir livremente quanto à participação nesta pesquisa e foi-lhes garantido o anonimato nas respostas.

\section{Coleta de dados e procedimentos}

Os dados foram coletados através de 9 fotografias de uma enfermeira (Anexo 1), com a mesma expressão facial, postura corporal e distância da câmera fotográfica; esta não usava nenhum adorno ou joia; os diferentes uniformes, por ela usados são descritos a seguir:

Foto 1 - saia branca, de comprimento abaixo do joelho e blusa branca; Foto 2 - calça comprida, blusa e blazer brancos;

Foto 3 - saia branca, de comprimento acima do joelho, blusa branca e blazer azul-marinho;

Foto 4 - calça comprida branca e blusa branca;

Foto i) - saia de comprimento abaixo do joelho, blusa e blazer brancos; 
Foto 6 - saia de comprimento acima do joelho, blusa e blazer brancos;

Foto 7 - calça comprida e blusa brancas com blazer azul-marinho;

$\underline{\text { Foto } 8}$ - saia branca, de comprimento acima do joelho e blusa branca;

Foto 9 - saia branca, de comprimento abaixo do joelho, blusa branca e blazer azul-marinho.

A escolha desses uniformes deveu-se ao fato de serem eles os mais comumente usados pela profissional enfermeira na cidade de São Paulo.

As fotos foram apresentadas concomitantemente aos elementos pesquisados, tendo sido perguntado qual a pessoa, das fotos mostradas, ele (a) escolheria para:

1. aplicar-lhe uma injeção;

2. verificar sua pressão arterial;

3. orientá-lo sobre suas dúvidas;

4. dar-lhe um banho;

5. examiná-lo, e

6. orientá-lo na alta do hospital.

Tais itens foram escolhidos por mostrarem atividades que demonstram cuidados (injeção, tomada de pressão arterial e banho), além de atividades consideradas pelo "senso-comum" como sendo mais intelectuais, como orientação do (a) paciente.

Em seguida, foi pedido para que escolhessem também em qual das fotos a pessoa lhe parecia mais ou menos confiável, inteligente, tranquila, segura e prestativa.

Esses itens são parecidos com os utilizados por MANGUM et al. (1991) nos Estados Unidos, no seu trabalho sobre uniforme, os quais foram escolhidos com base numa escala previamente testada por outros autores por ele citados, como os traços que mais aparecem na imagem que o público faz ou cita da profissional enfermeira.

Os dados por nós citados foram coletados no período de $1^{2}$ de setembro a 16 de outubro de 1992, por duas das autoras e por duas alunas do curso de graduação, previamente orientadas sobre o objetivo da pesquisa e o modo de proceder na sua coleta.

\section{Resultados e comentários}

A foto de maior aceitação para prestação dos cuidados referida pelos pacientes, enfermeiros e docentes de enfermagem, foi a de número 4 , isto é, 
calça comprida e blusa branca, e o seu número para os pacientes e docentes, foi mais do que o dobro das citações obtidas pela segunda foto eleita por eles.

$\mathrm{Na}$ categoria das enfermeiras, também foi bastante escolhida a foto de número 3 - saia acima do joelho, blusa branca e blazer azul-marinho - principalmente pelo elevado número de escolha nos itens 3 (esclarecimento de dúvidas) e no item 6 (orientação para a alta), ou seja, atividades mais educativas que assistenciais.

Examinando separadamente os itens de trabalhos manuais que a enfermeira faz (verificar a PA, dar injeção, dar o banho) dos itens considerados mais "intelectuais" (esclarecimento de dúvidas, orientação para a alta), vemos que na categoria pacientes e enfermeiras, a presença do blazer azulmarinho é alta para os itens de orientação (itens 3 e 6).

Podemos inferir, por esses achados, que a calça comprida pode ter sido escolhida por ser mais prática, permitir maior liberdade de movimentos nas ações, e que a escolha do uniforme da enfermeira ter sido toda em cor branca, deve-se a nossa compreensão social que os profissionais de saúde da área hospitalar normalmente, e há mais tempo, usam só a cor branca no seu uniforme. O uso do azul-marinho, apesar de já ser comum na cidade de São Paulo, entre enfermeiras, ainda está mais associado a imagem de outros profissionais. Um paciente, por exemplo, afirmou que, com o blazer azul-marinho "fica-se parecendo aeromoça".

O blazer aparece com maior freqüência nas atividades onde a verbalização é mais presente do que o fazer, por ser, talvez, uma vestimenta mais formal na nossa compreensão cultural.

Quando perguntamos sobre os traços de confiabilidade, segurança, inteligência, tranquilidade e prestatividade, a foto n.4 (calça comprida e blusa brancas) continuou aparecendo em $1^{9}$ lugar na escolha das categorias de pacientes e docentes. Na categoria de enfermeiras, o uniforme mais escolhido por esses traços profissionais foi a saia acima do joelho e blusa brancas e blazer azul-marinho (foto n.3), uniforme bastante votado por essa categoria na escolha de quem gostaria que cuidasse de si.

Não encontramos diferenças significativas na escolha dos traços positivos ou negativos; por exemplo, um uniforme sugerindo confiabilidade e um outro diferente sugerindo tranquilidade. Verificamos que, normalmente, a escolha do uniforme que a pessoa fazia para um traço, se repetia nos outros.

Foi verificado também, que os uniformes eleitos para as enfermeiras "cuidarem" dos outros, pelas 3 categorias profissionais, foram tamberm os mais votados na escolha dos traços profissionais positivos, ou seja, a vestimenta considerada mais adequada para aplicar injeção, dar banho, orientar nas dúvidas, é também a que inspira maior confiança, segurança, etc.

Por outro lado, os uniformes mais aceitos foram pouco citados quando 
a pergunta era "quem lhes parecia menos confiante, tranquila, segura, inteligente e prestativa".

$O$ uniforme mais rejeitado pelas 3 categorias pesquisadas foi a saia acima do joelho, blusa e blazer brancos (foto n.6), mas a saia acima do joelho e blusa branca (sem o blazer) também foi altamente rejeitado pelos pacientes e docentes (foto n.8).

Um dado interessante é que das 9 fotos, 3 mostravam a saia acima do joelho e, vemos que duas dessas fotos foram as mais rejeitadas na contagem geral.

É bom ressaltar que muitos pacientes (24) não quiseram eleger a enfermeira que lhes parecia menos confiante, tranquila, etc. Eles não hesitavam em apontar quem escolheriam para cuidar, os traços positivos, mas não escolhiam uniforme com conotação negativa. Podemos inferir que, apesar de termos feito o levantamento em diferentes instituições (umas com uniforme estabelecido, outras não), os pacientes possam se sentir intimidados em levantar aspectos negativos ligados à enfermeira, já que ainda dependem dos seus cuidados enquanto in ternados.

Lembramos que, no trabalho de MANGUM et al. (1991), realizado nos EUA, os pacientes preferiram o uniforme vestido branco e touca, enquanto, na nossa pesquisa, a preferência foi para o uniforme calça e blusa brancas. Não foram usadas fotografias de enfermeira com touca no presente trabalho, pois na maioria dos hospitais paulistanos as enfermeiras não a utilizam. Sabemos que nos EUA o uso de touca está incorporado à cultura americana, enquanto aqui no Brasil isso não ocorreu. A touca está mais ligada à figura estereotipada da enfermeira, na maioria das vezes, veiculada pelos meios de comunicação de massa, do que ao reconhecimento cultural da população a respeito da enfermeira. Não tivemos paciente algum que questionasse a ausência da touca nas fotos apresentadas.

\section{CONSIDERAÇÕES FINAIS}

Os dados encontrados nesse estudo são diferentes da pesquisa americana. Lembramos que as pesquisas realizadas em outros países só deverão ser validadas no Brasil, se forem consideradas as diferenças culturais e nivel social, econômico, educacional, climático, entre outros, que provocam uma percepção diferente da realidade nas pessoas.

Pudemos verificar também que a profissional mulher já está liberada para usar calça comprida, vestimenta que por muitos anos foi uma indumentária exclusivamente masculina, tanto que não se permitia à mulher adentrar nos recintos religiosos e forenses com tal vestimenta. 
Tal evolução é mais sentida ainda na enfermagem, quando lembramos, que há pouco mais de 20 anos, não era permitido o uso de calça comprida como uniforme da enfermeira. Hoje vemos pacientes escolhendo enfermeiras de calça comprida (foto n.4) para prestar assistência.

Isso mostra que a enfermagem, como todas as outras profissões, não pode ficar à margem das rápidas evoluções culturais que têm acontecido neste final de século. Nosso reconhecimento profissional junto à população também depende da nossa capacidade de inserção junto as transformações que estão ocorrendo no dia-a-dia.

SILVA, M.J.P. da et al. The nurse uniform as it is seen by patients, nurses and nursing school faculty. Rev.Esc.Enf.USP, v.29, n.1, p.72-82, Apr. 1995.

The exact role of the way people dresse up on the nonverbal communication is still unknown. Nevertheless, we know that it influences the interpersonal answers and, in some situations, they are the main determinants of those answers. The objective of this study was to determinate differences between the perception os the nurse uniform through the answers of 100 patients, 30 nurses and 15 nursing school faculty. The data were colected by showing nine photographs of hospitals of the city of São Paulo (Brazil). White trousers and blouse was the favorite one among patients, nurses and nursing school faculty regarding personal care. White skirt above knees, white blouse and blazer was the most rejected one by three groups.

UNITERMS:Uniforms. Nonverbal communication.

\section{REFERÊNCIAS BIBLIOGRÁFICAS}

BIRDWHISTELL, R. L. Kinesis and context. Philadelphia, Univ. Pennsylvania Press, 1970.

EYSENCK, H.; EYSENCK, M. Comportamento. São Paulo, Abril/Ć́rculo do Livro, 1981.

HOGA, L.A.K. Os uniformes da EEUSP: análise de sua evolução por meio de fotografia. /

Trabalho apresentado na Sessão Poster da Semana de Enfermagem, São Paulo, maio,1991/.

KALISCH, B.J.; KALISCH, P.A. Dressing for sucess. Amer. J. Nurs., v. 85, n. 8, p. 887-94, 1985.

KALISCH, P.A.; KALISCH, B.J. The image of the nurse in motion pictures. Amer. J. Nurs., v. 82, n.4, p. 605-11, 1982. 
KNAPP, M.L. La communicacion no verbal. Barcelona, Paid6s, 1980. cap. 5, p. 143-73: Los efectos de la aprencia física y la ropa.

MANGUM, S. et al. Perceptions of nurses' uniforms. Image, v. 23, n. 2, p. 127-30, 1991.

MEADE, H.A.C. Or no uniform at all? Nurs. Times, v. 76, n.4, p. 147-48, 1980.

MELO, M.R.A. da C. Como é a representação da(o) enfermeira(o) nos anúncios de publicidade? In: SIBRACEN, 2, Ribeirão Preto, 1990. Anais. Ribeirão Preto, 1990. p. 122-46.

MEYER, D. Children's responses to nursing attire. Pediatr Nurs., v. 18, n.2, p. 157-60, 1992.

SANDOVAL, J.M.H. Signos hospitalares: uma questão de comunicaçăo enfermeiro/paciente. In: SIBRACEN, 2, Ribeirão Preto, 1990. Anais. Ribeirão Preto, 1990, p. 658-77.

WEIL, P.; TOMPAKOV, R. O corpo fala: a linguagem silenciosa da comunicação não verbal. Petrópolis, Vozes, 1986. 


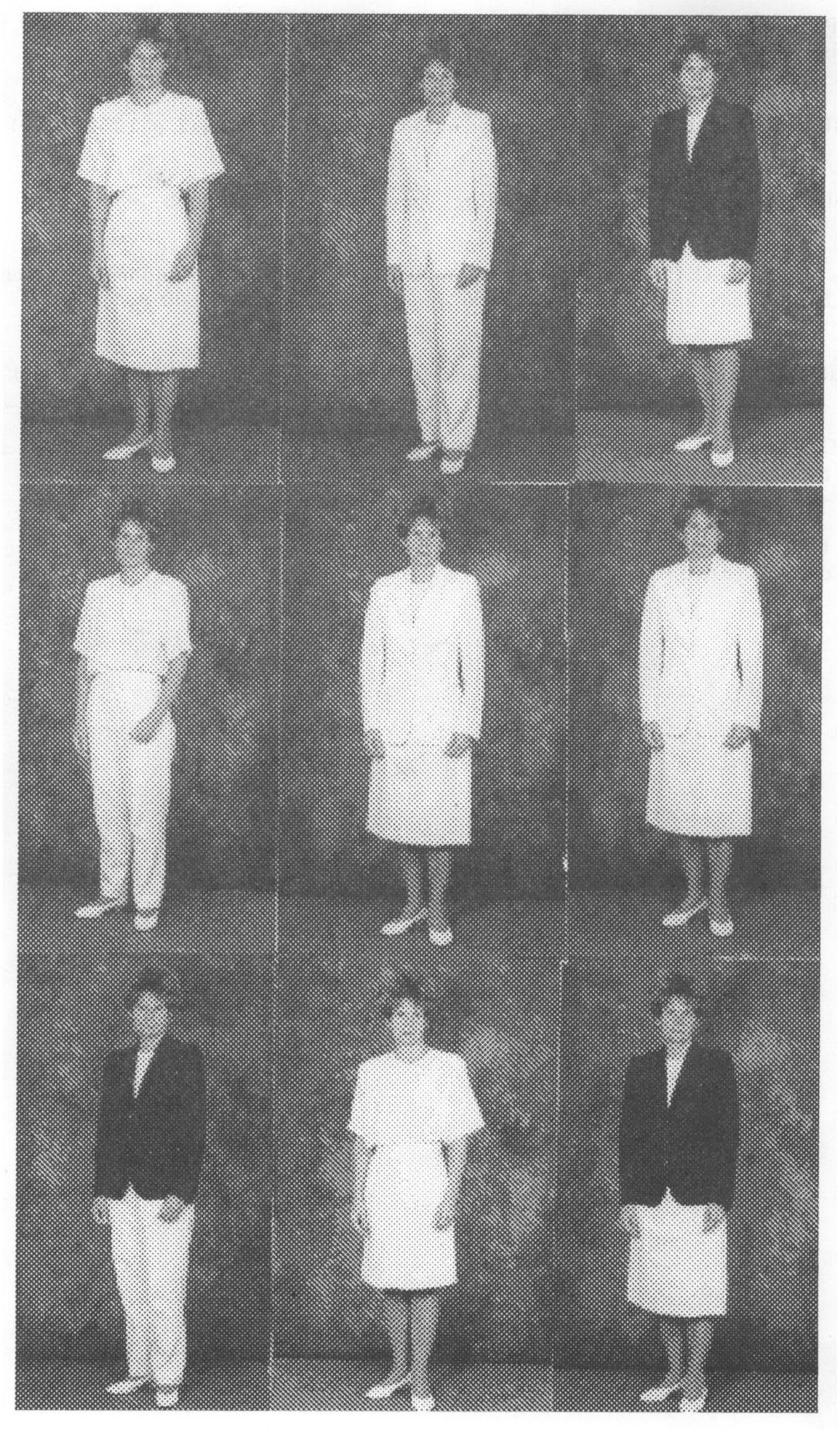

